\title{
TEACHERS' COURSES IN SPANISH
}

\section{By J. WARSHAW}

$\mathrm{W}$

ITH the establishment of a course in the teaching of Spanish at Yale, the acute situation in our field receives special emphasis. It undoubtedly points to further similar action both in the endowed and in the state universities. In some of the latter, such teaching courses have been given for some time: yet the example of Yale, Harvard, Princeton, Chicago, whether in the way of salaries or of scholastic advancement, has always carried uncommon weight and will continue to do so for many years, in spite of the late Professor Royce's reported conviction that within fifty years the state universities would be the leading centers of learning in the country.

The growth in the number of teacher-training courses in the languages should not be eyed with suspicion. They have in themselves nothing to do with the possible exaction of a degree in education,-a contingency "viewed with alarm" by many of our best language teachers. Professor Northup has summed up their sentiment in one of his admirable bibliographical paragraphs (Hispania, May, 1920, p. 165): "The author thinks that the time is near when a degree in education will be exacted of all language teachers. Such a tendency is evident in several states. Many of us believe that in so far as university and college teachers are concerned this would be retrogression and not progress. There are too many teachers in the country who think they can dispense with necessary content courses in favor of courses in education."

Between the offering of a specific course in the teaching of Spanish and the requirement of a degree in education, there is a wide gap which, perhaps, ought never to be bridged. I do not suppose that anybody can object to a training-course in languages or in a language, particularly since it is usually short and does not prevent extensive and intensive content-preparation. The mere word "pedagogy" or "education" ought not to prejudice us against a positive good.

Not only should teacher-training courses in the languages be tolerated, but the number of them should be increased. Our 
profession is a teaching profession, after all; and there is, or ought to be, such a thing as teaching. The genuine teacher is probably born, like the poet: and, like the poet, he must learn something about his art after he is born. The American Association of Teachers of Spanish could take no wiser step than to outline a set of minimum requirements in content and in the methods of teaching content and to use all its influence in having these requirements accepted and regarded by school authorities. The present dearth of teachers makes it almost obligatory to unite in concerted action toward a high standard. There is real danger that the shortage in teachers may result in a weakening of professional morale. The war, low salaries, and the readjustment due to conditions in German and in the classical languages have already occasioned a grave situation in the teaching of the Romance languages.

If we aim at careful instruction in our subjects, we must make it practically impossible for any teacher in the country to believe that a smattering of the language aided and abetted by a total ignorance of the rudiments of teaching will enable him to hold on in high schools or even in some colleges. We must likewise so arrange our professional work as to preclude the query on the part of Spanish or French clerks or salesmen as to why they should not be occupying high university positions in view of their intimate knowledge of their own language. Questions of this sort have not been unknown. In the first of the cases mentioned, lack of grasp of the language should seal the fate of the teacher, and in the second, inability to teach American students, where such inability is evident or probable, should have the same effect, no matter how critical the teaching situation may become. The first case should not be difficult to handle provided there is uniform agreement throughout the schools as to minimum preparation. The second case, whether applying to foreign or to American teachers, offers greater trouble, since not only is such a thing as professional preparation for teaching generally unrecognized, but even the usefulness of such preparation is matter of debate.

Nevertheless, few serious teachers are likely to deny that there is enough substance in a teaching course in languages to justify attention to it two or three hours a semester. This should be true above all for Spanish. Possibly separate teaching courses in 
French, Spanish, and other languages involve duplication: and it may be that a flexible, general teaching course in the languages, rather than an individual course for each language, would prove more economical and quite as effective. For the present, perhaps, distinct teaching courses would seem to have the best chances of success, though combined courses with individual oversight of practice classes have in some instances been managed advantageously.

The factors which enter into a consideration of teaching courses in Spanish are numerous, of ten unusual, and frequently unappreciated. A greater mass of informational material must be presented and more detailed directions given for self-orientation than in the other languages. The benefits or want of benefits in the use of phonetics, the problem of which Spanish pronunciation to teach to American students, the apparent conflict between the purely practical and the literary, the possibilities in the way of educating students about the Hispanic American countries, the question as to how much propaganda work is advisable and necessary, and how the steady attempt to depreciate Spanish may be met, the relative merits in Spanish of the "direct," the "natural," or the "translation" method, the encouragement of backbone in the treatment of students even if the enrolment should suffer somewhat,- a thing much feared by an extremely large proportion of teachers, though never admitted,- the furnishing of inspiration to prospective teachers who have not delved deep in Spanish, the opportunities for self-development in Spanish and in Spanish affairs, the desirability of membership in the national association of teachers of Spanish and in a local chapter, are vital points not likely to be taken up outside of a strictly professional teaching course. Some of these questions, though solved acceptably for the teachers of other languages, have not been solved for Spanish teachers.

Other elements less specifically Spanish must, moreover, be taken up with students who have never taught. Many of them may be nothing but trade-matters, such as the way to go about getting a position in Spanish, how and where to apply for one or for scholarships and fellowships for advanced study, what sections of the country offer the widest educational opportunities for teachers of Spanish, the writing of applications, private agencies 
and government agencies, salaries in Spanish in different cities and states, foreign countries in which a knowledge of Spanish is an asset, summer schools in Spanish for teachers, and the like. Perhaps the objection may be made that this is shoddy, that students who cannot do these things or find out about them for themselves do not deserve to hold a teaching position, and that it has nothing to do with the teaching of Spanish, anyway. I fear that this attitude is a near kinsman of that sanctimonious attitude which urged young people to go out and teach, glorying in the conviction that, though the worldly rewards might be small, the spiritual rewards were beyond compare. Actual direction of a few classes dispels toplofty ideas of this kind. We discover that thoroughly earnest and sensible students are of ten all at sea in these significant trifles, and that they have nobody to whom to go for advice unless the teacher of teaching is willing and able to give it. Of course, as soon as we encourage students to think of teaching our subjects, we assume certain responsibilities, and we cannot safely wave them aside with a scholarly air.

How to teach Spanish is, though, the main concern of the courses under discussion. By that is meant "how to teach Spanish grammar, translation, composition, and conversation." The teaching of literature is another story. On the whole, the principles which apply to the teaching of French, Italian, German, or Portuguese will obtain here also. That is why, in its broader aspects, an excellent manual like Mr. Lawrence A. Wilkins' "Spanish in the High Schools" seems to some teachers rather indefinite, in that its pedagogical treatment savors too much of all foreign languages and not enough of Spanish by itself. But it could not be otherwise, in the nature of the case. What nobody has any reason to complain of is Mr. Wilkins' facts about the growth of Spanish in its teaching aspects, his detailed course of study, his "bibliography and other aids for the teacher of Spanish," and his enthusiasm.

The topics under which a profitable course in the teaching of Spanish may be outlined are almost innumerable, even when we eliminate the vague terms "psychology," "child-psychology," "class-psychology," and their congeners. Not improbably, a study of "teacher-psychology" combined with an investigation of 
the effects of dyspepsia on teaching might, to many, seem more to the point. For the sake of experiment, the following leading topics may be suggested as a nucleus for the pedagogical substance of a course in the teaching of Spanish,- or of any foreign language:

1. Methods or devices.

2. Practice classes.

3. Observation and criticism of practice teachers and of other teachers in the vicinity.

4. Analysis of courses of study and the formulation of an original course of study.

5. Critical examination of text-books.

6. Minute examination of a particular grammar, with criticism and suggested improvements, including a survey of vocabularies.

7. Study of Spanish examination-papers, among them, those prepared by the College Entrance Board, with a view to understanding the scope and value of examinations.

8. Regular preparation of lesson-plans, that is, detailed written outlines of exactly what the teacher expects to teach, and how, on the following day.

9. Backward-student tests.

10. The use of a question-box.

11. School libraries, plays, clubs, debates, and the social side of language work.

Very brief reflection will convince even those most skeptical about teaching courses that each one of these topics has important ramifications and that the intending teacher can devote the necessary time and thought to them only in a teaching course. It is no exaggeration to assert that practically every specialist in the languages who has been interested solely in content, has left college and taken up his own teaching work without an adequate realization of the meaning of these and similar matters. True, they learn much in the language journals, but these can never take the place of a general survey and actual experimentation.

Four of the suggested topics deserve special explanation. The others speak for themselves.

The keystone of any course in teaching is the practice class. Without it, all judgment on a student's ability is guess-work, and the course, though valuable even then, becomes too much like a theoretical course in physics without laboratory facilities. Since 
the directors of teaching courses are sure to be consulted about teachers, they should have ample opportunity for watching their students under fire. Besides, there is no other means for practicing what has been heard preached. In universities supplied with a practice or model high school, the problem is taken care of. In universities not so supplied, arrangements may be made with the regular high schools either through the use of members of the teaching course as substitute teachers on occasion or through the regular employment of such students by a system of alternation. It is assumed that the students will have had the requisite training in the language before being accepted in the teaching course. The only question which arises in connection with these practice classes is the possibility of injustice to the children in placing them under unskilled teachers. On the other hand, teachers who have never taken a teaching course in the languages are unskilled and their charges are under the same handicap as the children in the practice schools until the teachers have gathered experience. The chances that the members of a teaching course will make fair teachers, at least, are normally good. As a lasst resort, where no practice school is available, a practice class may be formed in the university or normal school by selecting students out of the elementary courses who will be helped by additional instruction, or else, by turning the members of the teaching course into pupils protem. The latter shift is not recommended. It is mentioned as serving a useful purpose sometimes.

With a practice class, the whole teaching course gains cogency and coherence. Supervision by the director,-who should be relieved of other work for this task which takes time and energy,and observation by students become feasible. Critical analysis of methods, discipline, personality, and progress can be undertaken on a solid foundation. The application of tests of various sorts may be carried on. The formulation of lesson-plans, which is of the utmost significance for beginners, becomes practicable and the inspection of their adequacy in actual class-work, possible.

Few things are more helpful to the teacher than the outlining of lesson-plans. A lesson-plan is only another form of pedagogical preparedness. It should be written out and preserved, thus serving as a record of what has been done daily and having such subsidiary uses as the furnishing of specific information on the 
ground covered and the methods employed in any given period. Presumably, every teacher prepares lesson-plans, but not all put them on paper in tangible shape. The labor involved need not be excessive. The experienced teacher will find an ordinary filingcard large enough and can easily keep all the cards for each class together for reference in an envelope pasted within the back cover of the text-book used. The practice teacher will find it wisest to keep a book of lesson-plans extended in detail day by day. The confidence secured through such bona fide planning cannot help standing for much in a mastery of the subject if faithfully continued, and the dissatisfaction created by a long series of monotonous and identical lesson-plans cannot but stimulate pedagogical thought and the spirit of inquiry. It is to be feared that if the mental lesson-plans of many teachers were reduced to paper, they would read: 'Grammar, pp. 31-4, etc.: rules; read in Spanish; translate; composition; verbs.' Aside from the question of interest, whether on the part of the teacher or on the part of the student,- some teachers pretending to a horror of attempts to interest the students, as an obstacle to thoroughness, though their own thoroughness and anxiety for thorough work may well be doubted,-the purely mechanical preparation indicated above and the often as purely mechanical system for conducting classes are scarcely worthy of persons who have spent time and money in getting ready to enter a liberal profession. If that is all there is to teaching, then I should be inclined to sympathize with the belief that cheap help is perfectly satisfactory for the elementary language courses. Nor should I complain if my subject, by the very nature of it, were characterized as "inferior."

Nearly as essential as preparedness by means of lesson-plans is preparedness through an understanding of texts as texts. When, under ordinary conditions, the student leaves college, he has an acquaintanceship with the limited number of books which he has used. But it must be observed that he has known these books simply from the standpoint of the student, and may commonly think of them separately only by the color of their covers. They have been tasks to him, not instruments. He has probably never given a thought to them as teaching equipment. As soon as he becomes a prospective teacher, his viewpoint must necessarily change. There are texts and texts,- "and then some!" 
Almost any text can be employed with fair success either in the high school or in college, the teacher and the student being superior to any book made or to be made, but certain texts are, of course, better arranged and better adapted to certain stages than others. A careful study of the presentation of lessons, length and kind of vocabulary, subject-matter, teaching-aids, exactness of editing, general attractiveness, including typography and binding, should be a sine qua non of any teaching course. Some day, somebody will write an article on text-book prefaces, showing that many of them resemble, in their genial display of language, those college catalogs which emphasize the unsurpassed location of the institution, the unique charms of the climate, the inimitable dignity and picturesqueness of the campus, and the unequalled opportunities for social life. Not every text can be ordered on its preface, on the advertisements of the publishers, or even on the reviews. The best way to know a book is to go through it and without doubt principles for the analysis of texts may be formulated if they are not already available. Anybody who buys any kind of instrument, implement, or utensil, likes to feel that it will do fairly efficiently the work for which it was designed.

It stands to reason that the Spanish teacher should be familiar with the merits and defects of as many texts as possible; and a scientific analysis of them is indispensable before actual teaching begins. If nothing else were accomplished by this study, the acquisition of some principles for judging would repav the time spent. Naturally, special attention to texts presupposes a good library of modern texts along with some old texts for comparison.

A final suggestion is that a question-box into which anonymous slips may be thrown with impunity should be at the disposal of students in every teaching course. The discussion of these slips in class may not settle anything definitely, but it encourages reflection, sharpens the observational faculties, and stirs the imagination,--perhaps unduly. The young intending teacher deserves all the sympathy in the world. $\mathrm{He}$ is to face scores of pairs of scrutinizing eyes and to be under direct surveillance by his superiors in high schools or under indirect surveillance in colleges, and the sensation is about as agreeable as that of taking your first dictation in a business-office. Before he gets into action, he has many qualms and questions. The director of a teaching 
course can dissipate many of his doubts, answer some of his questions, and above all put him in the right frame of mind. If the student has some practice teaching to do, his queries will be the more pertinent and the aid which he receives the more beneficial.

A limited number of queries taken practically at random from a question-box to which contributions were made by one of my classes in the teaching of Spanish may be of interest:

Will the memorizing of vocabulary which is not used every day be of much benefit?

In planning a lesson for a modern language class, how can the teacher make the lesson unified, especially when a lot of ground must be covered?

Can much provision for individual differences in students be made in the teaching of a language?

To what interests and aims of the student should one appeal in planning a lesson in Spanish?

Would you advise a student to take beginning Spanish and second French, or vice versa, at the same time? I appreciate the fact that first Spanish and first French should not be taken together.

With due respect to conversation, should not the main emphasis be laid on grammar and reading?

How is it possible to get the real, exact meaning of a page of Spanish unless you translate the words and the phrases either consciously or unconsciously? I think it is all a question of the amount of vocabulary you know. I defy anybody to get the meaning of a page of Homer or even Xenophon by merely going over it half a dozen times unless he knows most of the words or forms. (This was handed in by the timidest girl in that particular class.)

Is it worth while for a teacher to compile a list of idioms for the students and have them learn a certain number each day?

Why should the direct method of teaching discourage the reading of books for content?

When a teacher reads sentences that have been prepared by the pupils to be translated from Spanish to English, and the students seem to do it well, may she feel that they are able to understand spoken Spanish? 
Can any provision be made for the self-conscious student in languages?

I cannot pronounce the jota without a tremendous amount of labor. Do you think there is anything the matter with my soft palate?

May the same methods be used in teaching high school students that are used in teaching college students?

Is it absolutely necessary to teach Spanish pronunciation by the use of phonetics? How can we find the time to do that and a lot of other things?

Why are some educational authorities so strenuously opposed to having the pupils do any written work in elementary language study?

Would it not be better to present the definite article to a class before the gender of nouns?

Can an all-Spanish book be used successfully in a high school?

What is the use of teaching those points in which Spanish usage and English usage are alike?

For how many hours of consecutive language teaching can a teacher be efficient in one day?

Some of the pleasantest teaching I have done has been in teaching courses. The work has been stimulating to me personally, whatever effect it may have had on the students. I honestly believe that it never degenerated into "hot air," as so many teachers are afraid must be the case in pedagogical discussion. Some things, I have learned, teaching courses cannot furnish. They cannot supply that priceless, though inexplicable, asset, personality; and personality is more than half the battle in teaching. But they can encourage personality by recognizing it and emphasizing its value; they can even help it by advice and by criticism of undesirable tricks or mannerisms; and they can sometimes almost create it by evoking it where it lies latent. Outside of personality, teaching as professional work can be taught in a teaching course, and it should be taught there. I do not "view with alarm" but "point with pride" to the increase in the number of teaching courses.

University of Nebraska 